\title{
Rehabilitation after severe brain injury: a follow-up study of a behaviour modification approach
}

\author{
PETER EAMES, RODGER WOOD \\ From the Kemsley Unit, St Andrew's Hospital, Northampton, UK
}

SUMMARY Twenty four patients with severe brain injury who had disturbed behaviours preventing rehabilitation or care in ordinary settings were treated in a token economy. This long-term follow-up study indicates that post-traumatic behaviour disorders can be lastingly improved, and that lengthy rehabilitation can have surprisingly good effects.

A significant proportion of those who suffer severe head injury develop, as a more or less direct result of their injury, disorders of behaviour which impede or prevent physical, social and occupational rehabilitation. Often rehabilitation therapy staff are unable to cope with such patients, and find their demeanour and lack of motivation discouraging and frustrating, as well as frightening. Many such patients find their way to psychiatric, geriatric or mental handicap hospitals, where they are very out of place. The usual result is a lack both of rehabilitation and of treatment of the behaviour disorder. Often there is progressive worsening of the behaviour disorder.

The nub of the problem is to find a way of managing behaviour which will produce cooperation and effort from the patient to allow therapists to apply their skills, and also allow the patient to learn the behavioural controls needed for him or her to become acceptable in the outside or "real" world.

Behaviour Modification (in a Token Economy setting) has been practised for many years with patients who show disorders of behaviour similar to those of the head-injured, though from different causes. ${ }^{1}$ The approach has been successfully applied in various clinical settings, and, to our knowledge, the only group of patients who have failed to gain long-term lasting benefit has been the chronic schizophrenic group. However, there seems to have been no previous attempt to apply the approach to the problem of the rehabilitation of head-injured patients with behaviour disorders.

For the past five years, we have been involved in

Address for reprint requests: Dr Peter Eames, The Kemsley Unit, St Andrew's Hospital, Northampton NN1 5DG, UK.

Received 10 May 1984 and in revised form 3 January 1985. Accepted 12 January 1985 the development of a specially organised unit (The Kemsley Unit) devoted to just such an attempt, ${ }^{23}$ and the purpose of this communication is to present the detailed findings of an extensive follow-up study of 24 of the first patients who were treated in the unit.

Space will not permit a discussion of the principles and background of Token Economy work, and readers are referred to the extensive reviews by Kazdin, Davey, Wood and Eames, and Wood. ${ }^{3-s}$ The Kemsley Unit is a very structured, enclosed unit organised as a token economy, and using a wide range of physical, cognitive, behavioural, occupational and social techniques for treatment and training. The behavioural treatment is based on the positive reinforcement (with tokens, "goodies", privileges, and, above all, interest, attention and praise) of all appropriate and adaptive behaviours, and the strict avoidance of such reinforcement ("time out from positive reinforcement") in the face of inappropriate, maladaptive or socially unacceptable behaviours. ${ }^{2} 5$

We feel it is important to make clear how severe the behaviour disorders tend to be, by giving a few brief examples. One young man spent much of his time exploring and stimulating his rectum (with hand and even forearm), and had even undone two attempts at repairing his large prolapse with silver wire; as a result, he spattered the world around him with faeces, mucus and blood; in addition, he was both explosively and deliberately aggressive, had "written off" three cars belonging to his father, and had been twice discharged from a psychiatric hospital as unmanageable. Another young man (previously an amateur boxer) had spent three years in residential rehabilitation units, but had always managed to avoid any actual therapy by threatening or 
being violent to the staff, or by persuading porters or other patients' visitors to wheel him across the road to the pub; his father claimed his son beat him up at least twice each week-end, usually "in a blind rage"; he remained in rehabilitation units because his parents would not have him home, nor would any psychiatric placement accept him. Lastly, a middleaged woman talked incessantly, stole any car left unattended with its keys in and drove sixty miles to London (usually stopping at a Police Station and reporting herself), struck at staff with her handbag and other weapons, and frequently presented herself at hospitals with invented ailments (more than once insisting on smoking in the casualty theatre in the presence of oxygen cylinders in use); her marriage had broken up, her mother was too old and frail to look after her, and she was on the verge of being discharged from a residential home because of her behaviour, in spite of the fact that no alternative placement could be found which would accept her.

The present study was designed to compare the states of independence and social viability of 24 patients immediately before admission and at follow-up some six months to three years after discharge.

\section{The follow-up study}

\section{Subjects}

Of the first 30 patients treated in the unit, six were excluded: two had died at the time of follow-up, two were back in the unit for "top-up" treatment or "holiday relief", one had spent only a few weeks on the unit (this was at a very early stage, and she had proved to be completely inaccessible because of gross destruction of the dominant hemisphere), and the family of one refused to take part. (The exclusion of the two readmitted patients seems justified, since many of the parameters measured would otherwise be very confused. However, we should mention that both had shown significant improvement from their initial treatment periods, enabling them to be placed and coped with in improved care settings, and had shown only slight fall-off in behavioural control by the time of readmission, which in each case was at about two and a half years from discharge.)

The 24 patients were followed up the spring and summer of 1983 , and had been treated between the opening of the unit (January 1979) and September 1982, thus allowing a minimum follow-up period of six months. The range of follow-up was 6 to 39 months, with a mean of 19 months for head-injured patients (SD 9.6), and 18.8 months for the whole group (SD 9.3). Table 1 shows the main features of the group. Age and sex distributions are typical of head-injured populations, ${ }^{6}$ but all the patients had had very severe injuries as judged by coma and post-traumatic amnesia durations. (Coma was assessed from contemporary clinical notes where possible, with attention paid also to information from family members. Post traumatic amnesia was assessed from the patients' information, and
Table 1

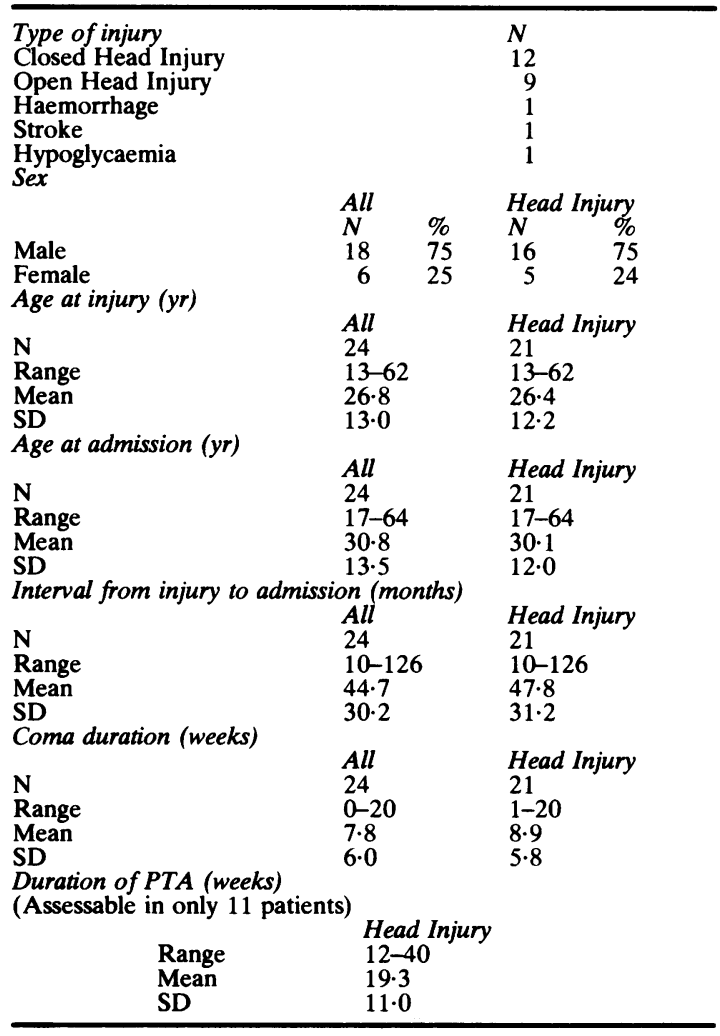

from descriptions from family members, not only of memory performance-many of the patients had persisting severe memory disorders - but of confusion.) In the great majority, the interval from injury to admission was very long indeed, the mean being nearly four years, so that virtually no expectation of spontaneous recovery existed; ${ }^{78}$ were therefore think it reasonable, in assessing outcome of treatment, to consider the patients as their own controls.

Because the lesions produced by head injury are characteristically rather diffuse, multiple and varied, it is difficult, short of individual case descriptions, to give a clear view of the actual patterns of brain damage shown by the patients in the study. However, it may be helpful to give the numbers of individuals falling into very broad groupings of types of patterns of damage, as judged on clinical and investigative grounds. Nine patients had mainly severe brainstem damage. One each showed relatively pure frontal lobe damage or hemiplegia (the latter having suffered stroke). Eight had very mixed pictures of mainly forebrain damage. The remaining five, having suffered anoxia or other very diffuse insults, showed the typical boundaryzone, basal ganglia and hypothalamic lesion pattern of such insults."

A full range of Social Class was represented, with some skewing towards the upper end: there were nine patients of Social Class I and II, 9 of III, and six of Classes IV and V. 
Table 2 Length of stay in months

\begin{tabular}{lllll}
\hline & $N$ & Range & Mean & $S D$ \\
\hline All patients & 24 & $3-25$ & $12 \cdot 2$ & $5 \cdot 3$ \\
"Responders" & 18 & $3-25$ & 13.6 & $6 \cdot 0$ \\
$\begin{array}{l}\text { "Responders" with full } \\
\text { treatment period }\end{array}$ & 12 & $3-25$ & $15 \cdot 6$ & $5 \cdot 8$ \\
\hline
\end{tabular}

Lengths of stay on the unit are shown in table 2.

\section{Method}

Treatment phase assessment Each patient's placement and placement prospects before admission were known, and used as the baseline for any change of prospects. At regular intervals during admission, and shortly before discharge, rating scales of behaviour and functional ability were completed as parts of the overall assessments. (Copies of these are available from the authors.) It was inevitable that some of the details of the scales changed on a number of occasions during the development of the unit, as increasing experience was gained. As a result there were too few patients with comparable rated items to allow statistical evaluation. However, in most cases (the exceptions being those earliest discharged) there was full comparability between pre-discharge and follow-up behaviour rating scales. For the functional (ADL) ratings, there were fewer patients with adequate comparability, since this scale underwent more revisions (see tables 7 and 8).

Follow-up assessment All patients and their "carers" were visited by the same assessor. (The "carers" varied from parents or spouses to care staff and social workers in hostels, and nursing staff in hospitals, but wherever possible there was an interview with a relative who was in regular contact with the patient.) A video-recording was made (with informed consent) to demonstrate mobility, speech and general psychological state. The patient and the "carers" completed questionnaires (copies are available from the authors) eliciting information about the current care setting, social activities, continuing treatment, and attitudes to treatment in the unit, and its effectiveness. The "carers" also completed rating scales concerned with behaviour and "activities of daily living" (ADL). These were shortened versions of the current scales in use on the unit, designed to allow proper statistical comparisons between the last pre-discharge scores and those at follow-up. Analysis of findings The most difficult problem was to find an objective overall measure of outcome. In large studies of outcome after head injury, the most usual factor measuring overall outcome seems to be employment. ${ }^{10}$ In the present group, however, all patients had imjuries of a degree of severity virtually never associated with return to

\section{Table 3 Hierarchy of possible placements}

1 Self care in own home possibly warden-controlled)

2 Own home, supervised (by family, friend or companion)

3 Own home, with active help from family, etc.

4 Own home, with active professional help (nursing, etc.)

5 Supervised Hostel

6 Care setting of Cheshire Home type

7 Long stay hospital (eg Royal Hospital and Home, Putney)

8 Psychiatric, Psychogeriatric or Mental Handicap Hospital work, and indeed none had achieved employment. Since the major impact of their behaviour disorders had been to make these patients unacceptable in either rehabilitation or care settings, we decided to construct a simple hierarchy of possible placements, and take as our overall measure the number of steps up (or down) this scale between admission, discharge and follow-up. Table 3 shows the scale. The ordering is based, not on the degree of personal independence required, but on the level of quality of life the placements afford, which matches well with the degree of control over behaviour needed for the placement to survive.

The "Carer's" Questionnaire findings were analysed for evidence of social outcome, need for continuing treatment, subjective view of outcome of treatment, and satisfaction with the treatment program. The Patient's Questionnaire findings were looked at in terms of the last two of these areas.

\section{Results}

\section{Overall outcome}

Table 4 shows the patients' placements before injury, before admission, on discharge, and at follow-up. (Since many were in very precarious placements at the time of admission, this is indicated in the table.)

Table 5 shows overall outcome at discharge (as determined by the placement to which the patient was discharged) and at follow-up. More than twothirds of patients had improved placements after treatment, and in all but one the improvements were substantial. Only one person slipped out of the "improved" group between discharge and followup, and five had made further gains. Fewer than a third had made no change from before admission, but none was worse placed.

There was no trend towards relapse as length of follow-up increased. Percentages of patients improved with follow-up of up to one year, one to two years and more than two years were 63,86 and 67 respectively. On the other hand, there was some relationship between outcome and length of stay on the unit. Fifty three percent of patients staying up to one year were improved, compared with $91 \%$ of those staying more than a year. In part this undoubtedly reflects the fact that six patients were identified during the first year as "non-responders", and were therefore discharged early.

Table 6 shows the surprising finding that the outlook for a good response to treatment was not affected by the length of time since injury.

There was no correlation between outcome and either sex or social class.

Perhaps the most interesting relationship was that between poor outcome and a history of one or other of the very diffuse insults (anoxia, ischaemia or 
Table 4 Placements from before injury to follow-up

\begin{tabular}{|c|c|c|c|c|}
\hline Placement & Pre-injury & Pre-admission & Disch. & $F U$ \\
\hline $\begin{array}{l}\text { 1 Living alone or with spouse, independently } \\
\text { 1a Living with parents, independently } \\
2 \text { At home with supervision } \\
3 \text { At home with family help and care } \\
4 \text { At home with professional help and care } \\
5 \text { In supervised hostel } \\
6 \text { Cheshire Home type } \\
7 \text { In long stay hospital } \\
8 \text { In psychiatric, geriatric or mental handicap hospital } \\
8 \text { a Long-term in acute hospital } \\
8 \text { b In rehabilitation unit }\end{array}$ & $\begin{array}{r}13 \\
11 \\
0 \\
0 \\
0 \\
0 \\
0 \\
0 \\
0 \\
0 \\
0\end{array}$ & $\begin{array}{l}0 \\
0 \\
0 \\
10(9) \\
2 \\
0 \\
1(1) \\
0 \\
4 \\
4(4) \\
3(3)\end{array}$ & $\begin{array}{l}1 \\
1 \\
3 \\
9 \\
0 \\
3 \\
0 \\
4 \\
3 \\
0 \\
0\end{array}$ & $\begin{array}{r}3 \\
1 \\
12 \\
0 \\
0 \\
2 \\
0 \\
3 \\
3 \\
0 \\
0\end{array}$ \\
\hline
\end{tabular}

(Numbers in brackets indicate patients for whom long-stay psychiatric placements were being actively sought)

hypoglycaemia): all five such patients had very poor outcomes, and, indeed, all appeared resistant to the treatment approach.

\section{"Carers"” Questionnaire}

Placements Sixteen of the 24 patients were living at home at the time of follow-up: 11 were with their parental families, two with spouses, one with a paid companion, and two alone. On the other hand, four were in psychiatric hospitals, three in residential physical-handicap centres, and one in a Social Services hostel.

Continuing treatment Twenty patients were still taking regular medication (though this included psychotropic drugs only for those in psychiatric hospitals, and for two patients taking lithium carbonate,

Table 5 Overall outcome

\begin{tabular}{lcc}
\hline $\begin{array}{l}\text { Steps of change } \\
\text { (see Table 4) }\end{array}$ & \multicolumn{2}{l}{ No of patients } \\
\cline { 2 - 3 } & Discharge & Follow-up \\
\hline+3 or more & 3 & 5 \\
+2 & 8 & 11 \\
+1 & 7 & 1 \\
+1 or more & 18 & 17 \\
0 & 6 & 7 \\
-1 or less & 0 & 0 \\
\hline
\end{tabular}

Table 6 Overall outcome related to interval from injury to admission

\begin{tabular}{lclllll}
\hline Inj-Adm & $N$ & \multicolumn{5}{l}{ No improved } \\
\cline { 3 - 6 } & +3 & or more & +2 & +1 & $A l l$ \\
\hline Up to 1 year & 2 & 0 & 2 & 0 & 2 \\
1 to 2 years & 5 & 0 & 1 & 0 & 1 \\
2 to 3 years & 3 & 0 & 1 & 1 & 2 \\
3 to 4 years & 5 & 1 & 3 & 0 & 4 \\
4 to 5 years & 5 & 2 & 3 & 0 & 5 \\
5 years + & 4 & 2 & 1 & 0 & 3 \\
Totals & 24 & 5 & 11 & 1 & 17 \\
\hline
\end{tabular}

both of whom had a pre-accident history of affective disorder). Eighteen were still receiving some sort of rehabilitation therapy (physiotherapy, occupational or industrial), and nine were using some sort of physical aid (five of them including wheelchairs).

Six patients had needed hospital admissions since discharge (as distinct from discharge placements), all of them for intercurrent physical illnesses, and all of them brief.

Social aspects At the social level, 16 of the 24 patients were said to be actively pursuing hobbies or premorbid interests, 12 were described as having "a reasonable social life", but only three had retained friends whom they saw on a regular basis. Only 11 went out regularly into the community, and five of these were regarded by their "carers" as having a disconcerting effect on the public. (On the other hand, considering that all of the patients had long been intolerable at home or in rehabilitation settings, it was gratifying to find that six were now regarded as "acceptable" in public.)

Attitudes to treatment Twenty patients were considered to have improved during admission. Thirteen were said to have improved further after discharge. In 17 cases, "carers" were happy with the treatment program, three were unhappy with some aspects of the method, and in five cases they thought it was ineffective.

Adequacy of placement At the time of follow-up, only 14 patients were regarded as being in the most suitable placement for their needs. The main reasons given for considering placement unsuitable involved lack of facilities for continuing physical or occupational rehabilitation, or despair that psychiatric hospital was the only setting available which could contain the patient.

Patients' Questionnaire

Attitudes to treatment Sixteen patients thought their condition was better at follow-up than before admission, and all of these thought they were now 
Table 7 Behaviour ratings (scored out of 10: $10=$ worst)

\begin{tabular}{|c|c|c|c|c|c|c|c|}
\hline \multirow[t]{2}{*}{ Category } & \multirow[t]{2}{*}{$N$} & \multicolumn{2}{|c|}{ Pre-discharge } & \multicolumn{2}{|c|}{ Follow-up } & \multicolumn{2}{|c|}{ Paired $t$} \\
\hline & & Mean & $S D$ & Mean & $S D$ & t value & $p<$ \\
\hline $\begin{array}{l}\text { Manipulation } \\
\text { Aggression } \\
\text { Sexual behaviour } \\
\text { Self-injury } \\
\text { Irritability } \\
\text { Social presentation } \\
\text { Drive and motivation } \\
\text { Odd behaviour }\end{array}$ & $\begin{array}{l}22 \\
22 \\
21 \\
21 \\
22 \\
15 \\
21 \\
22\end{array}$ & $\begin{array}{l}2 \cdot 1 \\
1 \cdot 8 \\
0 \cdot 7 \\
1 \cdot 0 \\
3 \cdot 4 \\
2 \cdot 5 \\
3 \cdot 0 \\
1 \cdot 9\end{array}$ & $\begin{array}{l}1.5 \\
1.3 \\
0.6 \\
1.6 \\
1.7 \\
1.6 \\
1.5 \\
1.9\end{array}$ & $\begin{array}{l}2 \cdot 8 \\
2 \cdot 3 \\
2 \cdot 2 \\
1 \cdot 5 \\
4 \cdot 0 \\
3 \cdot 0 \\
4 \cdot 7 \\
4 \cdot 5\end{array}$ & $\begin{array}{l}1 \cdot 6 \\
0 \cdot 2 \\
2 \cdot 1 \\
1 \cdot 9 \\
2 \cdot 0 \\
3 \cdot 0 \\
2 \cdot 1 \\
3 \cdot 5\end{array}$ & $\begin{array}{l}-2.64 \\
-2.83 \\
-4.43 \\
-0.05 \\
-1.13 \\
+0.62 \\
-4.51 \\
-3.17\end{array}$ & $\begin{array}{l}0 \cdot 2 \\
0.01 \\
0 \cdot 001 \\
\text { ns } \\
\text { ns } \\
\text { ns } \\
0 \cdot 001 \\
0 \cdot 01\end{array}$ \\
\hline
\end{tabular}

better than at discharge. One thought he did not improve during treatment, but had improved since discharge-and both his family and the treatment team agreed with this assessment. The remaining seven patients did not respond to the question.

Eleven patients said they had liked being on the unit, seven said they did not (mainly because they disliked having their freedom restricted), and six did not answer the question. On the other hand, of the 16 who answered the question, 15 thought that their admission was the reason for their improvement. Adequacy of placement of 16 who answered the question, 12 thought they were now in the most suitable place for their needs. Two others said they were bored and did not have enough activities available to them, one wished to live alone instead of with parents, and one was somewhat frightened by the responsibilities of independence.

\section{Behaviour Rating Scale}

Comparisons between admission and discharge ratings were not possible in enough patients to allow statistical analysis, because of the evolution of the Rating Scales mentioned above. Examination of individual patients' ratings during the course of admission showed progressive improvement trends in "responders", and this is attested, of course, by the fact that these patients became behaviourally acceptable at home or in the community at large.

This study was designed to investigate, among other things, the durability of behavioural changes brought about by behaviour modification. The comparisons between discharge and follow-up are shown in table 7, and indicate that there was little tendency for reappearance of troublesome behaviours after leaving the very structured behaviour management system. Inappropriate sexual behaviour and deliberate self-injury increased significantly in most patients, but the absolute scores are quite low. Odd behaviour increased to moderate levels, and this may reflect the difficulties for the treatment team of maintaining a sufficient awareness of the impact of odd appearance on the community at large. Drive and motivation are clearly rather fragile aspects of behaviour, and for many patients the stimulation of a busy structured program does seem to be missed.

\section{Activities of Daily Living Rating Scales}

Again, usable data were limited by progressive scale revisions, but where they are possible (table 8), similar comparisons of Activities of Daily Living ratings between discharge and follow-up show no significant loss of ability levels regained during treatment. The table shows the mean ratings. In fact a quarter of the group were unchanged from pre-admission states, and 10 patients scored close to $100 \%$ in at least five of the seven areas of ADL at follow-up.

\section{Discussion}

This study is concerned with 24 extremely severely

Table $8 A D L$ ratings (scored out of 10: $10=$ best)

\begin{tabular}{|c|c|c|c|c|c|c|c|}
\hline \multirow[t]{2}{*}{ Category } & \multirow[t]{2}{*}{$\boldsymbol{N}$} & \multicolumn{2}{|c|}{ Pre-discharge } & \multicolumn{2}{|c|}{ Follow-up } & \multicolumn{2}{|l|}{ Paired $t$} \\
\hline & & Mean & $S D$ & Mean & $S D$ & t value & $p<$ \\
\hline $\begin{array}{l}\text { Mobility } \\
\text { Table Habits } \\
\text { Personal Hygiene } \\
\text { Activities } \\
\text { Social Independence } \\
\text { Cooking } \\
\text { Personal Care }\end{array}$ & $\begin{array}{r}18 \\
18 \\
17 \\
17 \\
15 \\
9 \\
15\end{array}$ & $\begin{array}{l}8 \cdot 0 \\
8 \cdot 2 \\
8 \cdot 2 \\
6 \cdot 7 \\
6 \cdot 8 \\
6 \cdot 5 \\
6 \cdot 7\end{array}$ & $\begin{array}{l}3 \cdot 0 \\
1 \cdot 9 \\
2 \cdot 4 \\
2 \cdot 7 \\
3 \cdot 0 \\
3 \cdot 6 \\
2 \cdot 8\end{array}$ & $\begin{array}{l}7 \cdot 2 \\
8 \cdot 3 \\
7 \cdot 4 \\
6 \cdot 4 \\
6 \cdot 6 \\
6 \cdot 6 \\
6 \cdot 0\end{array}$ & $\begin{array}{l}3 \cdot 3 \\
2 \cdot 5 \\
3 \cdot 2 \\
3 \cdot 5 \\
3 \cdot 2 \\
3 \cdot 0 \\
4 \cdot 0\end{array}$ & $\begin{array}{l}-1.95 \\
-0.48 \\
-1.91 \\
-2.20 \\
-2.36 \\
-0.86 \\
-1.84\end{array}$ & $\begin{array}{l}\text { ns } \\
\text { ns } \\
\text { ns } \\
0.05 \\
0.05 \\
\text { ns } \\
\text { ns }\end{array}$ \\
\hline
\end{tabular}


damaged patients, the effects of whose injuries included disorders of behaviour which were serious enough to debar them from rehabilitation, and to make them unwelcome for further care, either at home with their families, in general hospitals or hostels, or often even in psychiatric hospitals. The results of the follow-up study show very clearly that a high proportion of these individuals could achieve dramatic and lasting improvements in behaviour and (thanks to consequent accessibility to rehabilitative interventions) in personal and social independence, in spite of long delays between injury and the beginning of rehabilitation. It should be emphasised that we have measured outcome in terms of the quality of life available to the patients in settings to which, as a result of treatment, they gained access.

At the same time, one quarter of the patients failed to gain any benefit from this treatment approach, either in behaviour or in rehabilitation. As experience has grown over 5 years, the unit team has become more able to predict in the first few weeks of admission which patients are unlikely to respond to the behaviour management system. Although detailed discussion is beyond the scope of this report, six of the seven patients who failed to respond to the treatment approach in this initial group of 24 would currently be considered unsuitable for admission on referral assessment, or would be recommended for discharge within six weeks of admission. This has resulted from the gradual recognition of a particular pattern of characteristics of behaviour and of the insult to the brain. (In fact, of these six, five were those with the very diffuse insults, and the other was a man with a life-long history of severe psychopathy, who suffered a stroke.)

In the present study, it was not possible to investigate fully the effect on outcome of the delay between injury and treatment, since none of the patients had early rehabilitation in the usual sense of "early". Only one patient was admitted less than a year after injury (11 months), and he achieved less improvement than was predicted, but this was more likely to be because he was discharged prematurely (after 6 months) because of funding problems. There is a natural assumption that the greatest improvement is likely with the least delay, and a comprehensive follow-up study from the USA ${ }^{11}$ strongly supports this view. Certainly we have no evidence against it. However, there is one particular circumstance in which it may not be correct: six patients in this group (and several others we have seen since) with severe brainstem injuries did have some measure of intensive rehabilitation therapy early on after recovery of consciousness, but with very little success; yet when rehabilitation was made available some years later, they showed very considerable improvements physically. It may be, therefore, that there are factors involved in brainstem injury which impose a necessary delay before recovery processes can be harnessed.

This study demonstrates that many severely brain-injured patients who currently cannot be accepted into rehabilitation programs can be successfully treated by combining formal rehabilitation with behaviour modification techniques. It also raises some wider questions.

Length of stay in the program was determined (where possible) by achievement and tempo of improvement. As long as measurable improvements were appearing at a rate which suggested that further achievements could be made costeffectively, treatment was continued. It is useful to look more closely at the thirteen patients who stayed up to one year. Six were discharged because they were thought to have very little probability of responding. One was discharged because very severe dysphasia made him virtually inaccessible, although active behavioural problems (aggression and repetitive shouting) had been diminished to the extent that he was acceptable in a long-stay care setting. Another made unexpectedly rapid progress (and had a very good overall outcome at follow-up). Four were removed because of lack of funding. And one was discharged after 7 months with little sign of behaviour change, but on return home was vastly improved.

In practice it was the fact that behaviour modification needs very lengthy application to achieve changes likely to endure that mainly determined the length of stay. As a result, rehabilitative treatments were able to continue for much longer than is usual, and extend into social, leisure and even occupational areas. The frequent finding that gains in functioning could continue to appear over such long periods has considerable implications for rehabilitation planning. Although one patient achieved full independence in all areas (except employment in the open market) within just a few months, the results overall do suggest that a period of treatment of some 15 to 18 months is likely to be optimal for most.

In this context, it should be recalled that the present group consisted of patients whose injuries had occurred long before treatment began, and who had all been considered "stable", that is very unlikely to show further improvement. ${ }^{8}$ The results therefore suggest that, even years after injury, persistent and comprehensive rehabilitation can achieve changes significant enough to make worthwhile improvements in the quality of life. There is a generally held view (more readily apparent in medico-legal reports on head-injured patients than in the scientific litera- 
ture) that very little improvement in physical, psychological or behavioural state is to be expected after two or three years from injury. This view is said to be supported by the evidence of long-term follow-up studies (see ref 7 for review and exemplar, but also ref 12). It is therefore of considerable importance to note that none of these studies makes any mention of rehabilitation, nor is there any reason to assume that adequate rehabilitation cannot alter outcome. Indeed, the present study joins that of Evans $e^{2} a^{10}$ in suggesting the opposite.

It is known that a proportion of individuals suffering moderate or severe head injury also develop behaviour disorders which cause considerable social and occupational impairment: it may be that the use of similar behavioural treatment approaches could improve their outcome, whether or not they have need of specific physical or cognitive rehabilitation techniques.

Throughout the history of clinical application of the techniques of behaviour modification, and perhaps especially of token economy, there has been argument over the specificity of the approach. In particular, it has been suggested that the actual techniques are of no importance, changes in behaviour being accounted for simply by the amount of attention and interest directed towards patients in such structured and busy settings. There is, for example, a study ${ }^{13}$ purporting to show that contingent tokens are unnecessary, since similar outcomes were achieved in groups with and without them. However, both groups received contingent social reinforcement, and the study was quite short-term, and involved a great deal of active interest and actual presence by the investigating psychologists. We would argue that, when such a unit runs for a very long period of time in "real life" conditions, tokens play the vital role of being constant reminders to staff of the need for social and other reinforcements. They are, in fact, ever-present cues. Although individual case-studies ${ }^{3}$ support the view that the techniques themselves are of central importance, we would certainly accept that the argument is by no means proven. In the present context, however, we would make the point that the token economy structure has allowed rehabilitation to proceed successfully despite disorders of behaviour which had previously made it impossible. At very least, therefore, this approach has proven itself at the empirical level.

Finally, it is worth observing that long-term psychiatric care is costly. Although intensive behavioural treatment and rehabilitation are more expensive per unit time, nevertheless they are well justified if they lead to greater independence from very long periods of costly care.

\section{References}

' Kazdin AE. The Token Economy: A Review and Evaluation. New York: Plenum, 1977.

.2 Eames P, Wood RLI. Rehabilitation after severe brain injury: a special unit approach to behaviour disorders. International Rehabilitation Medicine 1985 (in press).

${ }^{3}$ Wood RLI, Eames P. Application of behaviour modification in the rehabilitation of traumatically braininjured patients. In: Davey G, ed. Applications of Conditioning Theory. London: Methuen, 1981:81101.

${ }^{4}$ Davey G, ed. Applications of Conditioning Theory. London: Methuen, 1981.

${ }^{5}$ Wood RLI. Behaviour disorders following severe brain injury: their presentation and psychological management. In: Brooks $\mathrm{N}$, ed. Closed Head Injury: Psychological, Social, and Family Consequences. Oxford: Oxford University Press, 1984:195-219.

' Field $\mathrm{JH}$. The epidemiology of head injuries in England and Wales. London: HMSO, 1976.

${ }^{7}$ Roberts AH. Severe Accidental Head Injury: An Assessment of Long-term Prognosis. London: Macmillan, 1979.

${ }^{8}$ Bond MR, Brooks DN. Understanding the process of recovery as a basis for the investigation of rehabilitation for the brain injured. Scand J Rehabil Med 1976;8:127-33.

9 Brierley JB. Cerebral Hypoxia. In: Blackwood W and Corsellis JAN, eds. Greenfield's Neuropathology. Chicago: Yearbook Medical Publishers, 1976:43-85.

${ }^{10}$ Evans CD, Bull CPI, Devonport MJ. Rehabilitation of the brain-damaged survivor. Injury Accident Surgery 1977;8:80-97.

"Severe Head Trauma: a Comprehensive Medical Approach (collaborative). Institute for Medical Research, Santa Clara Valley Medical Center, 751 South Bascom Avenue, San Jose, California 95128; November 1982.

12 Brooks DN ed. Closed Head Injury: Psychological, Social, and Family Consequences. Oxford: Oxford University Press, 1984.

${ }^{13}$ Hall JN, Baker RD, Hutchinson K. A controlled evaluation of Token Economy Procedures with chronic schizophrenic patients. Behav Res Ther 1977;15: 261-83. 